\title{
Pediatric Enigma in ICU - Late Treatment of Severe Sepsis: A Case Report
}

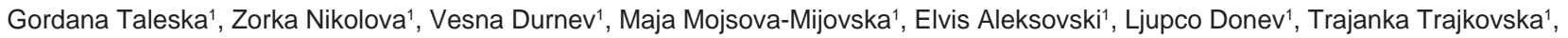

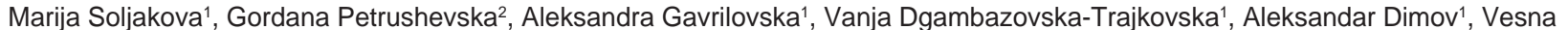
Cvetanovska $^{3}$, Vladimir Cadikovski ${ }^{3}$, Risto Simeonov ${ }^{3}$

${ }^{1}$ Clinic of Anesthesiology, Reanimation and Intensive Care, Faculty of Medicine, Skopje, Republic of Macedonia; ${ }^{2}$ Institute of Pathology, Faculty of Medicine, Skopje, Republic of Macedonia; ${ }^{3}$ Clinic of Pediatric Surgery, Faculty of Medicine, Skopje, Republic of Macedonia

Citation: Taleska G, Nikolova Z, Durnev V,
Mojsova-Mijovska M, Aleksovski E, Donev Lj,
Trajkovska T, Soljakova M, Petrushevska G,
Gavrilovska A, Dgambazovska-Trajkovska V,
DimovA, Cvetanovska V, CadikovskiV, Simeonov
R. Pediatric Enigma in ICU - Late Treatment of
Severe Sepsis: A Case Report. Maced J Med Sci.
2012 Jul 31; 5(2):189-193. http://dx.doi.org/
10.3889/MJMS.1957-5773.2012.0217.
Key words: nosocomial infections; sepsis;
propofol; disseminated intravascular coagulation;
ritual circumcision; children.
Correspondence: Dr. Gordana Taleska. Clinic
of Anesthesiology, Reanimation and Intensive
Care, Vodnjanska 17, Skopje 1000, Macedonia.
Phone: 023147039; Fax: 023112502. E-Mail:
gordana_taleska@yahoo.com
Received: $21-N o v-2011 ;$ Revised: $21-D e c-2011 ;$
Accepted:23-Dec-2011; Online first:28-Jun-2012
Copyright: $\odot 2012$ Taleska G. This is an open
access article distributed under the terms of the
Creative Commons Attribution License, which
permits unrestricted use, distribution, and
reproduction in any medium, provided the original
author and source are credited.
Competing Interests: Theauthors have declared
that no competing interests exist. that no competing interests exist.

\section{Introduction}

Outbreaks of nosocomial infections continue to occur in healthcare despite the available knowledge on this topic.In addition, postoperative infection is usually considered a matter related to the surgical procedure [1]. The conduct of anesthesia would also break the intactness of protection of the host.Further,the anesthetic agent in use if contaminated will introduce microorganism into the body either through respiratory tract, epiduralspinal procedure or intravenous route.

\section{The case}

Two brothers, 5 and 12 years old, foreign citizens from a neighboring country, underwent ritual circumcision in a private clinic in their country. Children were circumcised under general anesthesia with propofol/ fentanyl,after 9 hours of fasting. Intraoperative course went uneventfully. But several hours later, children began to vomit; parents didn't bring them to the clinic immediately, thinking it was post-anesthetic side-effect. Since boys' general condition deteriorated further,they 
were brought to the clinic next morning; lab tests showed increased ALT, AST, LDH and decreased platelets count.

Later that day, on parents' demand, children were transported to Skopje, first to another private clinic and afterwards to University Clinic of Pediatric Surgery. Pediatric surgeon on duty confirmed that circumcision was well done and surgical wound was clear. Childrens' general condition was deteriorated-they were somnolent and continued to vomit. Neurosurgeon was consulted; he didn't indicate brain CT-scan. Pediatric surgeon decided to treat by herself, without consultation of ICU doctors on duty. Then again, for convenience and expediency of care, next morning (approximately 36-40 hours after surgical intervention), patients were admitted in ICU at our Clinic. On admission their general condition was extremely difficult - older boy was agitated, younger one was somnolent.

They were both shivering; had warm, dry skin, interstitial edema; brown, stinky, mucous, loose stool; only younger brother had satisfactory urine output. The older boy had haematuria and oligo-anuria; was tachipnoeic and soporous with severe acidosis (BE= 13.9) and respiratory failure. He received CVC immediately and was put on inotropes. Monitoring included ECG, invasive blood pressure, CVP, $\mathrm{SaO}_{2}$, urine output; detailed biochemistry and acid-base status, microbiology, hepatitis viral markers, coagulation tests and CXR were completed; also, toxicologist, infectologist and pediatrician were consulted. Table below shows their laboratory data during the stay in ICU (Table 1).

Table 1: Laboratory findings in two brothers, 5 and 12 years old, underwent ritual circumcision.

\begin{tabular}{|c|c|c|c|c|c|c|}
\hline $\begin{array}{c}25.08 \\
(10: 00 \text { a.m.) }\end{array}$ & $\begin{array}{c}25.08 \\
(8 \mathrm{p} . \mathrm{m} .) \\
\text { (ABS: } 10 \text { p.m..) }\end{array}$ & $\begin{array}{c}26.08 \\
(8: 00 \text { a.m...) }\end{array}$ & $\begin{array}{l}\text { L.K. } \\
\text { (Younger } \\
\text { Boy) }\end{array}$ & $\begin{array}{c}25.08 \\
(10: 00 \text { a.m.) }\end{array}$ & $\begin{array}{c}25.08 \\
(8 \mathrm{pm} .) \\
(\mathrm{ABS}: 12 \mathrm{p} . \mathrm{m} .)\end{array}$ & $\begin{array}{c}26.08 \\
(8,00 \text { a.m.) } \\
\text { (ABS: 1 p.m.) }\end{array}$ \\
\hline 117 & 94 & 71 & & 125 & 119 & 102 \\
\hline 0.36 & 0.28 & 0.21 & & 0.39 & 0.34 & 0.298 \\
\hline 4.5 & 3.63 & 2.76 & & 4.8 & 4.6 & 3.97 \\
\hline 12.7 & 23.5 & $18.5 / 17.2$ & & 20.2 & 28.1 & $26.5 / 23.7$ \\
\hline 38 & 55 & 21 & & 55 & 57 & \\
\hline \multirow{4}{*}{5.0} & 130.9 & 133.2 & & 127 & 127.2 & 135.1 \\
\hline & 5.9 & 4.98 & & 4.4 & 4.5 & 4.52 \\
\hline & 102 & 100.3 & & 101 & 103 & 107.9 \\
\hline & 1.5 & 2.00 & & 1.7 & 1.45 & 1.78 \\
\hline 48 & 46 & 44 & & 44 & 43 & 44 \\
\hline 32 & 21 & 28 & & 29 & 18 & 28 \\
\hline 21 & 27.1 & 34.62 & & 20.9 & 20.1 & 31.02 \\
\hline 261 & 391 & 423 & & 178 & 141 & 233 \\
\hline \multirow[t]{2}{*}{3.6} & 2.7 & 2.81 & & & & 2.69 \\
\hline & 1.2 & 3.12 & & & 3.2 & 2.72 \\
\hline 7011 & 12615 & 4844 & & 14369 & 15059 & 6621 \\
\hline $89.1 / 63.9$ & & $78 / 59.56$ & & 72.9 & & $76.8 / 56.38$ \\
\hline 1323.4 & 1178 & 1075.5 & & 1896 & 2286 & 2536.4 \\
\hline 2518.6 & 2193 & 1659 & & 2978 & 3669 & 4359.4 \\
\hline & 90 & 128.8 & & 96.43 & 90 & 148.91 \\
\hline \multirow[t]{5}{*}{326.1} & & 245 & & & & 211.4 \\
\hline & 7.15 & & & & 7.31 & 7.325 \\
\hline & $72.0 / 87.3 \%$ & & & & $116 / 98.3 \%$ & $74.8 / 92.7 \%$ \\
\hline & 43.3 & & & & 19.7 & 19.0 \\
\hline & $\begin{array}{l}-13.9 \\
15.2\end{array}$ & & & & $\begin{array}{l}-16.2 \\
10.2\end{array}$ & $\begin{array}{l}-16.3 \\
10.0\end{array}$ \\
\hline
\end{tabular}

ICU treatment comprised of: early gold directed therapy, de-escalation antibiotic therapy, inotropes (dopamine+dobutamine), manitol, H2-blockers, hepatoprotective therapy, carbon medicinalis.

Older boy's condition got worse, hence he was intubated (at 8 p.m.) same day (followed by haemoptysis) and put on mechanical ventilation. Four hours later, ICU doctor on duty started with lung protective strategy. With $\mathrm{FiO}_{2}$ 0.6-1.0, the ratio $\mathrm{PaO}_{2} / \mathrm{FiO}_{2}<200$. By next morning, clinical presentation of DIC was more than evident. Transfusion treatment with FFP, PLT concentrates, cryoprecipitate didn't had much of an effect; the idea was to administer recombinant factor VIla. However, it is expensive and difficult to obtain. Unfortunately, while thinking of indications, contraindications and trying to provide the medication through the huge administrative labyrinth, older boy died (at 12 a.m.) (Fig. 1).

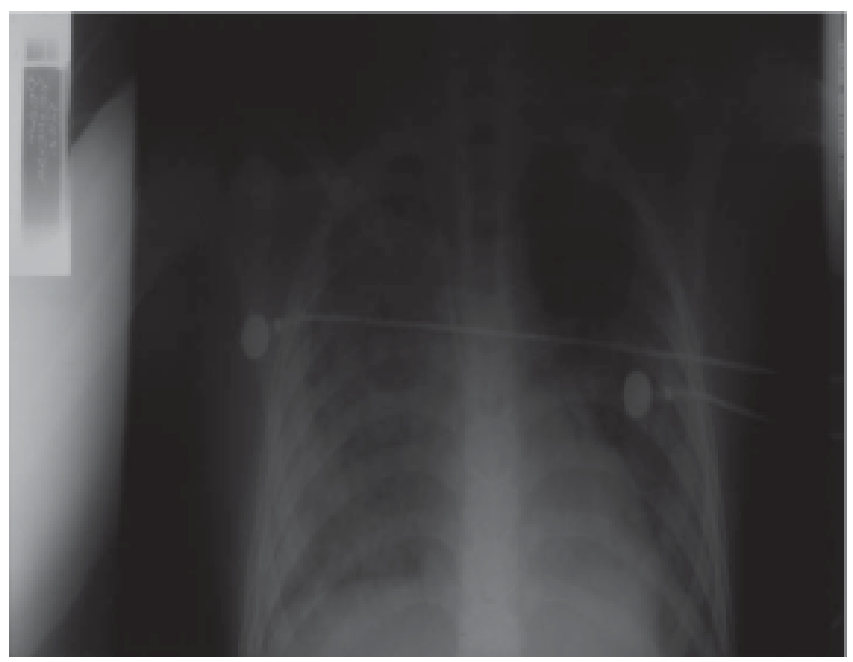

Figure 1: CXR of the older boy.

Most of the tests results from admission came afterwards:

- coagulation tests: PLT 35, PT 24s, aPTT 63s, TT 66s;

- toxins and viruses - negative;

- samples - Older boy: MRSA (nose); Younger boy: Enterococcus (circumcision wound);

- blood cultures - negative;

- pathohistology - showed Hemorrhagic syndrome propter Endotoxic shock.

The photographs below show most significant pathohystological finding (Fig. 2). 

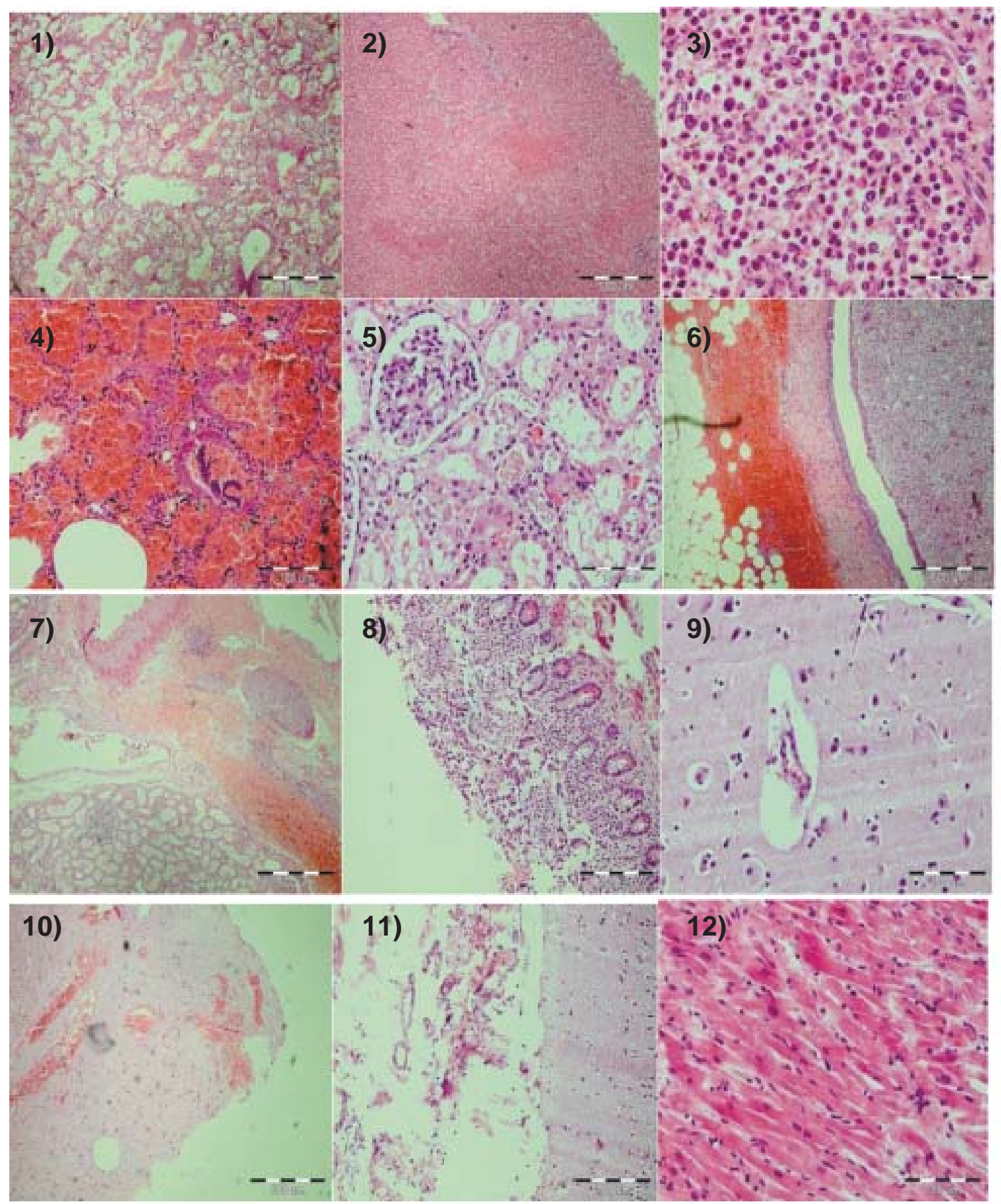

Figure 2: The photographs show the most significant pathohystological findings: 1) Lungs - ARDS; 2) Liver necrosis; 3) Spleen-with eozinophiles; 4) Bleeding in the lungs; 5) Kidney - ATN; 6) Kidney - pyelon; 7) Bleeding in the kidney; 8) Intestine; 9) Brain edema; 10) Brain stem bleeding; 11) Leptomeninges; 12) Myocardium.

At 5 p.m. same day, on request of the parents, younger boy was transferred to a Clinic in Germany. German colleagues informed us that they confirmed 'endotoxic shock' diagnosis; boy's general condition was stabilized while on mechanical ventilation with ultrafiltration. 


\section{Discussion} included:

The differential diagnosis in these cases

1) Sepsis / Endotoxemia.

2) Toxic fulminate acute liver failure with encephalopathy, HUS, HPS (toxic) - the toxicological tests ruled out this as being completely negative.

3) Acetyl-coenzyme A-dehydrogenase deficitperioperative fasting and (even emotional) stress can trigger metabolic decompensation through altered metabolism of endogenous fatty acids resulting in hypoglycaemia,acute cardiac and hepatic dysfunction and rhabdomyolysis. Considering reports about possible interference of propofol with fatty acid oxidation and avoidance of unnecessary administration of fatty acids, propofol should not be used in these patients [2]. The pathohystology excluded this syndrome.

4) Viral hemorrhagic fever (CCHF) - while we had information that children came back from holidays in a neighboring country which was endemic for CongoCrime hemorrhagic fever, we were not able (technically!) to confirm nor to exclude definitely this etiology (although the spleen showed presence of eosinophils, which is very indicative for a hemorrhagic fever).

'Modern' diagnosis of endotoxemia requests for usage of so called LAL kits - for endotoxin and cytokine measuring. Regrettably, these last technologic advantages are not on hand everywhere. Measuring procalcitonin is still expensive, but at least more accessible test for diagnosing sepsis and septic shock. However, we don't have technical opportunity to perform any of these tests.

One of the most important question from our point of view is the one regarding DIC and its treatment. $\mathrm{DIC}$ is a result of liver failure and is very often present in the clinical appearance of sepsis with MOF. Our older patient bled to death. Coagulation tests confirmed obvious clinical presentation. Regarding treatment of DIC, the most frequently asked question among doctors in ICU nowadays is the one concerning recombinant factor VIIa (rFVIIa). Is rFVIIa safe to use in DIC and sepsis?

Indications [4] for use of rFVIla are well established in the drug prescription list. Sepsis, however, is included in the list of pathological conditions in which tissue factor may be expressed more extensively than considered normal, meaning there may be potential risk of development of thrombotic events or induction of DIC in association with rFVIIa treatment. Therefore, administration of rFVIIa in these patients needs special precautions [4].

In their study [5] Goksel Leblebisatan et al. reported about 20 nonhemophiliac patients with hemorrhages that resolved with rFVIIa. Authors concluded that rFVIIa can be safely used in high-risk patients with recurrent hemorrhage. Anna Conen et al., in their study [6] informed about off-label use of rFVIIa. They summarized that large prospective, randomized, controlled trials were still missing, while guidelines concerning off-label use of rFVIla were urgently needed.

Let's go back on the source of infection. Infection in post-operative period should more or less bear relation to the operation [7]. Identified risk factors of postoperative wound infections include length of preoperative stay, length of operation, presence of other infection at time of surgery, and patient-specific factors. None of these risk factors could be found responsible for the acute septic shock. Thus, anesthesia related-factor as a cause of bacteremia was raised.

Our suspicion that contaminated propofol was source of infection was based on the fact that severity of septic shock that resembled intravenous injection of endotoxin in human was suggestive of the entry of the infectious microorganism by intravenous access, as well as exclusion of other causative factors.

Propofol-associated postoperative infections and the association of propofol with bacterial growth and production of endotoxin have been brought forward in many case reports and microbiologic as well as epidemiological laboratory studies [8].

As we presumed, diagnosis of endotoxic shock was most probably connected with the use of contaminated solution of propofol. A fact that supports this presumption is the information that these boys' cousin had circumcision in same clinic, done by same team and after same previous meal and holidays, but under local anesthesia.

Propofol (2,6 diisopropylphenol) is rapid and short-acting intravenous agent for induction and maintenance of general anesthesia, that contains soyabean oil. Emulsions of soyabean used clinically support bacterial growth.[9]. When bacterial contamination does occur, potential for severe morbidity (pyrexia, surgical wound infection, septic shock, ARDS,MOF) associated with use of propofol tainted in such a way is clear $[10,11]$. Paucity of reported cases of 
propofol-associated sepsis may reflect difficulty in identifying propofol as cause of sepsis. Alternatively, one might consider that it highlights low risk of developing a systemic infection following injection of bacterially contaminated propofol. This issue remains unresolved.

However, since this is a legal case in a neighboring country, we would like to leave out any further comments regarding this, particularly because no possibility existed to check and culture opened vials of propofol, as well as propofol-related devices.

Conclusion: Time is the most important factor when dealing with sepsis and septic shock. If golden period for treatment of sepsis is gone, its outcome is almost always catastrophic. Symptoms should be treated while searching for diagnosis. Unfortunately, there isn't a magic bullet, yet, regarding therapy. Team approach should be carried out without exception, and last but not least-we should all learn from our mistakes.

\section{References}

1. Stone HH. Infection in postoperative patients. JAMA. 1986; 81:39-44.

2. Steiner LA, Studer W, Baumgartner ER, Frei FJ. Perioperative management of a child with very-long-chain acylcoenzyme A dehydrogenase deficiency. Paediatric Anaesthesia. 2002;12:187-191.

3. Wyke RJ et al. Bacteraemia in patients with fulminate hepatic failure. Liver. 1982;2(1):45-52.

4. Package insert. Factor VIla [eptacog alfa] (NovoSeven). Novo Nordisk, June 2009.

5. Leblebisatan G, Sasmaz I, Antmen B, Yildizdas D, Kilinc Y. Management of life-threatening hemorrhages and unsafe interventions in nonhemophiliac children by recombinant factor VIla. Clin Appl Thromb Hemost. 2010;16(1):77-82.

6. Conen A et al. Failure of recombinant factor VIIa in a patient with severe polymicrobial sepsis and postoperative uncontrolled intraabdominal bleeding. BMC Infect Dis. 2007; 7:34.

7. Haley RW, Culver DH, Morgan WM, White JW, Emori TG, Hooton TM. Identifying patients at high risk of surgical wound infection. Am J Epidemiol. 1985;121:206-215.

8. Bennett SN, McNeil MM, Bland LA, Arduino MJ, Villarino ME, Perrotta DM, Burwen DR, Welbel SF, Pegues DA, Stroud $\mathrm{L}$, et al. Postoperative infections traced to contamination of an intravenous anesthetic, propofol. $\mathrm{N}$ Engl J Med. 1995;333(3):147-54.

9. Package insert. Diprivan (propofol). Wilmslow, UK: Zeneca Pharmaceuticals, 1996.

10. Center for Disease Control. Postsurgical infections associated with extrinsically contaminated intravenous anesthetic agent - California, Illinois, Maine, and Michigan. MMWR Morb Mortal Wkly Rep.1990;39:426-7, 433.

11. Veber B, Gachot B, Bedos JP, Wolff M. Severe sepsis after intravenous injection of contaminated propofol. (Letter). Anesthesiology. 1994;80:712. 